\title{
Colaborando a una Bibliografía de san Agustín
}

\section{XV CENTENARIO DE SU MUERTE (430-1930)}

(cf. Estudio Agustiniano vol. XLII, 2007, fasc. 20, 267-291).

105.- BURGOS, V., Hacia el XV Centenario de la muerte de San Agustín, en "La Ciudad de Dios", 144 (1926), 5-12.

106.- PINCHERLE, Alberto, Problemi di critica agostiniana, en "La Cultura" (Bologna), n. s., VIII-I-10 (1929), 607-621.

"Estamos al final de 1929 y en 1930 celebraremos el Décimoquinto Centenario de la muerte de S. Agustín". Se espera que las publicaciones sean abundantísimas, dice el autor. Y se pregunta: " $₫ A$ che punto é dunque la critica e quali sono $i$ quesiti che si presentano come piú urgenti?" (p. 607). Expone primero la crítica a la historicidad de las Confesiones y de la evolución de Agustín, a partir de 1888, de Harnack y Boissier pasando por Thimme, Alfaric, Boyer, Nörregaard, de Labriolle, Montgomery, Buonaiuti, Misch, Böhmer, M. Wundt, H. Dörrier, Reitzenstein, M. Zepf. Una buena síntesis que permite una clara visión de los problemas de la evolución de Agustín.

107.- Lettera del Rvmo. P. M. Eustasio Esteban, Generale degli Agostiniani per il XV Centenario della Morte del S. P. Agostino.- A cura del "Bolletino Storico Agostiniano”. Firenze, libr. Ed. Fiorentina, 1929, 11 pp.

Hay ediciones en diversos idiomas.

108.- AXTERS, Stephanus, $\mathrm{Na}$ vijftienhonderd Jaar!, en "Thomistisch Tijdschrift" 1 (1930), 595-612. 
Examen de algunas biografías de S. Agustín y qué debe ser una biografía agustiniana: "Een biographie moet eerst en vooral het verhaal zijn van een siel; gaat het om het leven van een denker, dau gaat het er vooral om den toelit dien zijn gedachteleven beschreven heeft te achterhacen en aundermadel te beschrijven" (p. 598-599).

109.- ADDEO, Agostino Felice, S. Agostino nel 15 Centenario della sua morte: 430-1930. Lettera pastorale. Nicosia, Tipografia edit. del Lavoro, $1929,86 \mathrm{pp}$.

En una bella impresión sigue este orden: Las dos célebres Conversiones, El hijo de tantas lágrimas, La educación cristiana, El siervo de Dios, monje y sacerdote, El obispo coadjutor, El Obispo de Hipona, El Pastor de almas, El Maestro catequista, El Seminario episcopal, La caridad del Obispo, San Agustín Iglesia - Estado, Las Confesiones, La Ciudad de Dios. - El Santo, en la liturgia, en el culto de los santos, en la vida divina, en el Transitus felix, en el XV Centenario.

110.- ANóNIMO, San Agustín, en “Criterio”(Buenos Aires) 130 (1930), 267 sgts.

111.- ANónIMo, Centenario Agostiniano, en "Rivista di Filosofia NeoScolastica” 21 (1930), 319 y 417-418.

Recuerda en esas páginas las conferencias habidas en el Instituto Católico de París con motivo del XV Centenario, y los números extraordinarios y misceláneas, ofreciendo el título de los artículos.

112.- BARDY, Gustave, Autour de saint Augustin, en "Supplément à La Vie Spirituelle” 25/3 (1930), (161) - (171).

"No podríamos pretender señalar aquí todos los libros, todos los estudios, todos los artículos de revistas consagrados a San Agustín en el curso de estos últimos meses; son demasiado numerosos y no cesan de llegar de todas partes nuevos libros, nuevas compilaciones, nuevos artículos, tan poderosa es la atracción que ejerce sobre las almas de hoy el alma del obispo de Hipona. Trataremos de recordar solamente, entre tantos trabajos, aquellos que presentan un interés especial debido a los problemas que abordan o que son más fácilmente accesibles a los lectores franceses" (p. (161). Y enumera un gran número 
de ellos, haciendo un brevísimo recuento de su contenido. En su mayor parte artículos y en francés.

113.- BERTRAND, Louis, Quinzième Centenaire de la mort de St.

$\therefore$ :Augustin. (Discours). Paris, Didot, 1930, 23 pp.

114.- BLOEM, W. A., Sint Augustinus oratorium voor Koor soli en orkest. Gedicht van P. Fr. W. A. Bloem, O.E.S.A.. Musiek Jam Nieland Kavieruittreksel. Rotterdam, W. L. e J. Brusse's Uitgmij N. V., 1930, 175 pp.

115.- BRIÈRE, Yves de la, Chronique du Mouvement religieux - Congrès eucharistique. Centenaire augustinien, en "Études” 203 (1930), 613618.

Relación del Congreso eucarístico de Cartago y de las visitas y actos realizados en lugares agustinianos.

116.- BLONDEL, Maurice, Le quinzième Centenaire de la mort de saint Augustin(28 août 430). L' unité originale et la vie permanente de sa doctrine philosophique, en "Revue de Metaphysique et de Morale” 37 (1930), 423-469.

"El estudio de Agustín plantea imperiosamente problemas que ningún filósofo podría ignorar o eliminar sin discusión: condiciones de una filosofía unificada e integral; de una tradición intelectual ligada a una disposición del alma entera, de una fijeza de orientación a través de las renovaciones inevitables y saludables; de una doctrina que, religiosa por su desarrollo espontáneo y no por accidente, continúa siendo esencialmente filosófica, aún acogiendo a los doctos inaccesibles a la sola razón: he aquí lo que Agustín nos guía a examinar, por poco que con entera libertad crítica quieran asir la significación de tesis que han jugado papel tan grande en la historia general del pensamiento" (p. 425). Examina diversos problemas para desprender la unidad, perennidad, totalidad, verdad de la vida y doctrina de Agustín.

117.- CAPELLAZZI, A., Nel $X V$ Centenario di S. Agostino. Un piccolo presente al Grande del pensiero. Crema, Lib. ed. "Buona Stampa", $1930,66 \mathrm{pp}$. 
Tras un Prólogo, estudia en modo breve y para divulgación : La personalidad de S. Agustín, La Ciudad de Dios -primera y segunda parte-, Las razones eternas aplicadas a la filosofía de la historia, La historia y el devenir humano, La Ciudad de Dios y la filosofía de la historia.

118.- CHENU, M. D. , Bulletin d' histoire des doctrines chrétiennes. III. Occident. Antiquité. Pour le XVe. Centenaire de S. Augustin (4301930), en "Revue de Sciences philosophiques et théologiques" 19 (1930), 569-581.

"Nous nous attacherons plutôt à discerner, à l'occasion des principales publications, les points de vue qu'on se plait a dégager. Nous signalerons ensuite quelques monographies" (p. 569-570). Y a este respecto examina a Gilson, recordando a Romeyer, a Grabmann, a Haesele, a Gardeil, a Servier, a Alves Pereira, a Saint Martin. Y recuerda al final brevemente monografías sobre las Confesiones, De Trinitate, la creación, la moral y la redención. No podemos, sin embargo, privarnos de algunas perlas de este artículo, por sus afirmaciones y el testimonio de un conocedor de la antigüedad clásica y del pensamiento antiguo cristiano. "De toute maniére -escribe-, le développement de la pensée chrétienne occidentale est commandé, à son entrée, spécialement en anthropologie et en sotériologie, par les expériences y par les doctrines de S. Augustin. Historien et théologien, chacun selon sa méthode, trouvent donc là un inépuisable sujet" (p. 569). Y dice todavía más: "La théorie de l' illumination est au coeur même de la "philosophie", de la sagesse, de la contemplation augustinienne. Invoquer l' autorité d' Augustin en éliminant cette illumination, c' est faire de la mauvaise histoire sous prétexte de poursuivre en théologie une vaine et inutile uniformité de la tradition". " $L$ ' un des meilleurs chapitres de $M$. G. (ilson) est précisèment celui où il interprète, avec beaucoup de discretion, l' illumination augustinienne, et par elle, toute la noétique(chap. V, 103-125). Nous ne pouvons qu'y renvoyer, ainsi qu' au paragraphe suivant(pp. 125-137), où 'la vie de l' âme est dècrite à partir de cette presence de l' âme à elle mème qu'est la memoria" (p. 573).

119.- D' ALES, Adhàmar, Sur la trace de saint Augustin, en “Études" 202 (1930), 81-88. 
Comentario a la obra de Gilson, recogiendo sus principales elementos para concluir en el Dios de la caridad de Agustín y en que su enseñanza no puede ocluirse en un sistema cerrado.

120.- D' ANNIBALLE, R., $A$ ricordo del $X V$ Centenario della beata morte di S. Agostino, vescovo e dottore. Lanciano, Masciangelo, 1930, 66 pp.

121.- ETCHEVERRY, Auguste, Un Hommage à S. Augustin, en "Revue Apologétique" 51 (1930), 51-57.

Presentación expositiva de los trabajos publicados en "Archives de Philosophie", vol. VII, Cahier II. Études sur saint Augustin.

122.- FABOZZI, Edoardo Alberto, Nel centenario di Aurelio Agostino. Le armonie di una vita e di un pensiero. Commemorazione. Pompei, Scuola tip. Pot. per i figli dei carcerati, 1930, 30 pp.

123.- FABOZZI, E. A., La parola di S. Agostino nel suo Centenario, en "Augustiniana", Napoli, 1930, 129-132.

La palabra de orden de los Centenarios es: "Risuscitare l' amore" (p. 129). Y en éste sentimos cerca al "Doctor de la Caridad". "Tutta la dottrina di S. Agostino è una teologia che diventa poema ed è un poema che rimane teologia: in questo egli non ha pari nella storia" ( $p$. 130). La palabra del Centenario Agustiniano es el amor y "solo cosí l' amore non sarà più un esule, ma sarà fremito e fiamma della nostra risurrezione" (p. 132).

124.- MONACO, Arminio de, Nel centenario di S. Agostino 430-1930. L' uomo e le opere, en "La Scuola Cattolica" $17 / 16$ (1930), 161-177.

“¿Qué angustioso pensamiento atormenta hasta la última hora su espíritu? ¿Quién ha sido aquel que la Iglesia honra sobre los altares con el título glorioso de doctor y padre de la fe? ¿Qué había hecho durante setenta y seis años de vida? He aquí las preguntas a que quisiera responder esbozando en una rápida síntesis alguna línea de su retrato espiritual, simple y grande, como ciertas figuras miguelangelescas" (p. 162). Sigue su vida paso a paso y desprende de ella su pensamiento y su ideario. 
125.- NYGREN, Anders, Augustinus. Ett 1500 - ârsminne, en "Svensk Teologisk kvartalskrift" 6 (1930), 223 - 230.

Reflexiones ante el Centenario de San Agustín con su tema de fondo el eros y el agape en la visión de las Confesiones.

126.- DURAN, José, Himno a San Agustín a tres voces iguales. En el XV Centenario de su Gloriosa Muerte. Barcelona, 1930, 6 pp. con música y letra debajo.

127.- De S. Augustino Episcopo Hipponensi et Ecclesiae Doctore, millesimo et quingentessimo ab eius obitu exeunte anno, "Ad salutem humani generis". Litterae Encyclicae Ssmi. P. Pii PP. XI. Datum Romae apud Sanctum Petrum die XX mensis Aprilis, in festo Paschae Resurrectionis D. N. S. J. anno MDCCCCXXX - Pontificatus nostri nono, Pius Papa XI.

Hay traducciones en casi todos los idiomas.

128.- Lettera Enciclica di S. S. il Papa Pio XI. Per cura dei Padri Agostiniani. Tipografia poliglotta Vaticana, $1930,55 \mathrm{pp}$.

129.- Litterae Encyclicae de S. Augustino, episcopo Hipponensi et Ecclesiae doctore, en "Acta Hebdomadae Augustinianae - Thomisticae", 1930, 17-47.

130.- RATTI, Achille, Rundschreiben unseres Heiligen Vaters Papst Pius XI über den Hl. Augustinus zu seinem 500. Todestag. (Ad salutem humani generis vom 20.4.1930). Übers. und erl. von Meurers. Trier, Paulinusdruckerei, 1930, $56 \mathrm{pp}$.

131.- ROCCA, Guglielmo della, Insegnamenti di Agostino, en "Augustiniana" 1930, Napoli, 133-134.

Breves frases con pensamiento agustiniano. "Le donne -escribehanno una parte non secondaria nella vita dell' insonne viatore: negativa, la femmina del senso e del errore; positiva, due donne elettissime: la madre, la sorella, che presedera quindi a case religiose" (p. 133). Y agrega en otro lugar : "La donna, considerata da pavidi cristiani qual demone, fu, da questo Padre, scorta in luce di angelo, dietro la traccia 
di Maria. Ed egli educò, e incoraggiò disputando non poche teologhesse del suo tempo. Prescriveva, tra l' altro, la cristiana modestia dell' acconciatura, vietava l' uso delle collane in memoria delle quasi ancor recenti martiri che avevano offerto il collo alla spada del carnefice" (p. 134).

132.- ROTONDI, G., Ricordo del $X V$ Centenario della morte di $S$. Agostino. Roma, tip. "Buona Stampa", 1930, 22 pp.

133.- SARNO, Luigi, $X V$ Centenario dalla morte di $S$. Agostino -28 agosto 430-1930. Conferenze e panegirico per--. Napoli, Stabilimento tipografico editoriale, 1930, $64 \mathrm{pp}$.

Contiene tres Conferencias sobre 1ra. S. Agustín y el progreso; $2 d a$. S. Agustín y la verdadera vía del progreso; 3ra. S. Agustín y la verdadera fuente del progreso. Y concluye con un panegírico: La grandeza de S. Agustín.

134.- SAWICKI, F., Swiety Augustyn Pierwszym Celowiekiem Nowozytnym, en ?Swity Augustyn", ed. S. Bross, Poznam 1930, pp. 222-237.

135.- SEEBERG, Reinhold, Augustinus, en "Nachrichtenblatt der Deutschen Wissenschaft und Technik. Forschungen und Fortschriften" 6 (1930), 307-308.

La llamada de Agustín en su Centenario como buscador incansable de la Verdad, de Dios. Dios es su objeto. "Gott zu gewiessen, ist das Ziel geistigen Lebens. Man sieht wie erkennen, Wollen und Gefühlsaffekte sich in diesem Streben unteinander Verbinden" (p. 307). Entre idealismo e Iglesia anda la historia de Agustín y la de nuestra época, decía.

136.- SEEBERG, R., Augustinus. (+ 28 August 430). Gedächtnisrede gehalten am 23. Jun. 1930 in der Aula der Universität. Berlin. Stuttgart, W. Kohlhammer, 1930, 40 pp.

137.- SEGURA, P., Pastoral del Card. Arzobispo de Toledo sobre S. Agustín con motivo del XV Centenario de su muerte, en "Boletín del Arzobispado de Toledo", abril 1930. También se ha publicado en "Religión y Cultura" y en "Archivo Agustiniano". 
138.- WESP, H., Nur einer ist euer Lehrer, en "Hessische Schulblätte" 6. 9 (1930).

139.- BAKEL, H. A. van, De oogst van Augustinus' jubeljaar, en "Nieuw theologisch tijdschrift" (Haarlem) 20 (1931), 134-154.

Resumen de artículos publicados en diversos homenajes y misceláneas del Centenario agustiniano. Los examina en torno al "método de la investigación agustiniana", la "teoría del conocimiento", la "conversión", Cassiciacum, Confesiones, Agustín como doctor de la gracia y su aportación al desarrollo doctrinal de la Iglesia católica (p. 136).

140.- EDER, Karl, Ernte des Augustinusjahre, en "Literarischer Handweiser" (Regensburg) 67 (1930-1931), 145 -148.

"Die besprochenen Bücher zum Augustinusjubiläum tragen ausnahmslos die Merkmale der Echtheit, ernste Beschäftigung mit dem grossem Gegenstand und Lieben au sich. Romeis, Krebs, Papini, Lang und Heimanns rücken mehr den Menschen, Gilson, Stohr, Wunderle und Bernhart das werk in den Börderquellgrund".

141.- PINTA, Miguel de la, Crónica del Centenario agustiniano, en "Religión y Cultura" 15 (1931), 510-521.

142.- RUSSO, Paolo, Sant' Agostino. Conferenza Scolastica Commemorativa del XV Centenario della morte. 430-1930. Loano, Tip. Giorgio Olocco, 1931, $18 \mathrm{pp}$.

Una exposición panegírica de la vida del santo, sin nervio científico ni mordiente erudito.

143.- BAYNES, N. H., $A$ note on the Fifteenth Centenary of the death of St. Augustine, en "History"(London) 36 (april 1931- january 1932), 193201.

Falta una biografía completa que abarque toda la vida de S. Agustín y ésa sería el mejor deseo y el fruto más preciado del Centenario, dice el autor, una vez que ha ofrecido un breve recorrido por los trabajos publicados en Europa occidental sobre san Agustín, cuya personalidad, agrega, atrae cada vez más a los estudiosos. 


\section{FORMACIÓN DE LA PERSONALIDAD DE SAN AGUSTÍN}

\section{A. Formación psicológica y social}

\section{Ambiente o medio geo-etnográfico}

144.- HOLMES , V. M. Dennis, Another note on the vandal occupation of Hippo Regius, en "The Journal of Roman Studies"(London), 15 (1925), 263-268.

"In conclusion, then, it may with great probability be asserted that the vandals raised the siège of Hippo Regius in 431; that, at some time not earlier than 432 nor later than 435, the city was temporarily abandoned by its inhabitants and partially burned by the Vandals; and that not later than 435 it had been reoccupied by the Romans" (p. 268).

145.- MOORREES, Franciscus Dionysius, Die organisatie van de christelijke Kerk van NoordAfrika in het licht van de brieven van Augustinus. Proefschrift. Groningen den Haag, J. B. Wolters, U. M., 1926, XI- 122 pp.

Tras una breve Introducción, desarrolla estos capítulos: I. Het bisschoppelik ambt als gronds lag voor de kerkelike organisatie; II. De grootte van het bisdom Hippo ten tijde van Augustinus de kerkelike verdeeldheid en het bevestigen van de "pax catholica"; III. De organisatie van het bisdom Hippo Regius; IV. Het ontstaan van bisdommen op het platteland van Noord - Afrika; V. Het verband tussen de kerkelike organisatie en het kerkelijke leven. Parroquias, presbíteros y donatismo se integran sobre todo en estas páginas.

146.- BUONAIUTI, Ernesto, Il cristianesimo nell' Africa romana. Bari, Gius. Laterza e Figli, 1928, XXIV - 454 pp.

En la historia del cristianismo africano ocupa un puesto privilegiado Agustín de Hipona (pp. 342-396). Le dedica en la II Parte los capítulos 6, 7 y 8 con estos titulares: La conversión de Agustín; Las polé- 
micas de Agustín; La síntesis agustiniana. El último está dedicado a La Ciudad de Dios, a la que habría dado su salida Ticonio. "Si Ticonio es donatista, san Agustín es incomprensible sin el donatismo. Así, desde el principio hasta el fin, el cristianismo africano es fiel a su vocación" (p. 450).

147.- DÖLGER, Franz Josef, Die Himmelkönigin von Karthago. Ein religionsgeschichlicher Beitrag zu den Schriften Tertullians, en "Antike und Christentum" 1 (1929), 92-106.

Sin embargo, no deja de citar a Agustín a propósito de Virgo coelestis, Dea magna en el famoso pasaje del De civ. Dei II, 26 (pp. 102104), y luego en algunas otras referencias en homilías (p. 106).

148.- DÖLGER, Franz Josef, Antike Parallelen zum leidendem Dinocrates in der Passio Perpetuae, en "Antike und Christentum" 2 (1930), 1-40.

En él hay un apartado, el 4, intitulado: Die eschatologische Beweitung der "Dinocratesvision" durch Vincentius Victor und Augustinus(pp. 20-28). Recoge el texto especial del libro De natura et origine animae II, 10, 14 y lo explica a la luz de la tradición y de la escatología.

149.- SAUER, Joseph, Der Kirchenbau Nordafrikas in den Tagen des hl. Augustinus, en "Aurelius Augustinus", 243-300.

La organización de la iglesia africana es tardía. Breve insinuación hasta llegar al donatismo, que inicia el "altar contra el altar" y se apodera de algunas basílicas católicas. Las informaciones más claras sobre la construcción de la Iglesia la tenemos en S. Agustín (p. 246) y la describe a partir de los textos del Santo(pp. 246-247), resumiendo las basílicas que había y los elementos que entraban en su construcción. Sigue una descripción histórica y arquitectónica de las iglesias y basílicas: 1 . De la Mauritania, con 12 ilustraciones, colocadas entre las páginas 256-257; 2. De la Numidia; 3. Del África proconsular y 4. De la Byzacena o Byzacium. Hace luego un amplio estudio de las catacumbas y de las pinturas y arte hallado en esas basílicas e iglesias, sintiendo no poder todavía completar el cuadro con las iglesias de la Provincia Tripolitana y Cyrenaica. 
150.- LAPEYRE, G. G., St. Augustin et Carthage, en "Miscellanea Agostiniana” II, 91-149.

151.- MORIN, Germain, Où en est la question de Cassiciacum?, en "La Scuola Cattolica” 55, Ser. VI -9 (1927), 51-56.

Contra los escépticos de la localización. Morin se alza contra Salvioni que excluía tanto Cassago como Casciago (cf. Della villa dove avrebbe soggiornato S. Agostino in Lombardia, 1899). Piensa que se ha apelado demasiado al argumento filológico para excluir a priori a Cassago y añade: "Il faut commencer par se convaincre de ceci: des diverses localités auxquelles on a songé, comme pouvant occuper l' emplacement de la villa de Cassiciacum, il ne reste aujourd' hui de possibilité qu' en faveur de Cassago de Brianza" (p. 53). Examina la situación geográfica e histórica de Casciago, Cazzago y Cassago y hace votos por que algun arqueólogo estudie este último.

152.- MEDA, Filippo, La controversia sul "Rus Cassiciacum”, en "Miscellanea Agostiniana", II, 49-59.

153.- MEDA, Filippo, Ancora il Cassiciacum di S. Agostino, en "La Scuola Cattolica" 9 (1927), 198-202.

A propósito del artículo de Morin, escribe al director contando la historia y la tradición. Casiciaco es Cassago de Brianza y hasta 1845 ninguno lo había dudado seriamente (p. 199). La duda se debe a Alessandro Manzoni que escribió una carta en respuesta a la de Poujoulat y le indicaba Casciago como lugar al que había que recurrir. Para Meda Cassago es incontestable y "quien tenga aún dudas consienta -dice- que se le llame incontentable"(p 202).

154.- KOORNHUYSEN, Félicien van den, $A$ Cassiciacum, en "Miscellanea Augustiniana”, 83-95.

"La conversión de Agustín se ha convertido desde hace cincuenta años en un problema histórico...Tomando a grandes rasgos las soluciones emitidas por los críticos puede establecerse entre ellos una izquierda, un centro y una derecha" (p. 83). Y expuesto eso con brevedad, agrega unas notas personales. "Agustín, en Casiciaco, con respecto a la Iglesia no era más que un catecúmeno" (p. 85). "Les 
Confessions, dit-on, nous présenteraient l' image d' un chrétien puisqu' accompli, d' une piété tendre, aux aspirations ardentes, les Dialogues au contraire celle d' un chrétien réservé et froid sur le chapitre de ses croyances, mais épris de philosophie, passionné pour la sagesse humaine" (p. 85-86). No se olvide que era un catecúmeno, responde el autor, y lo que la teología dice sobre él. A los que no creen y objeten que "las preocupaciones literarias y filosóficas de Agustín en Casiciaco son absolutamente incompatibles o al menos difícilmente conciliables con el estado de alma que supone una conversión”, les dice que "la nueva moralidad de su vida" está fuera de duda (p. 87). En cuanto a la filosofía que no está reñida con la fe y además que tenía "un deber de estado", dadas las condiciones en que se hallaba, rodeado de paganos(pp. 90-92). Termina con una breve bibliografía en francés sobre el tema.

155.- E. A. F., Carthage - Phoenician and Roman-, en "Fifteenth Centena$r y$ ", 52-59.

Cartago entre fenicia y romana ha desarrollado su vida. Breve examen, añadiendo más atentamente la "cristianidad en Cartago", siguiendo a Baronio y a algún otro autor, como Tertuliano, describiendo luego los años precedentes a San Agustín.

156.- FORAN, A. E., St. Augustine and the African Church, en "Souvenir of the Fifteenth Centenary of the death of St. Augustine" 430-1930, 6069.

Influencia de Cartago en Agustín desde los años de su educación hasta el auditorio que brindó a sus sermones, invirtiéndose más en el cisma donatista, sus causas y perspectivas.

157.- BRUYNE, Donatien de, Un texte de saint Augustin sur le culte de Cybéle, en "Theologische Revue” 30/5 (1931), 227-228.

Contra Dölger explica el pasaje de Tract. In Joan. VII, 6, como una transformación cristiana del culto a Cibeles y a Atis. Sería el dies sanguinis que en África se hacía caer de la oreja de Cibeles a la que robaron un pendiente de oro, y no de la castración de Atis. Se pregunta si la festivitas sanguinis se celebraba todavía el 24 de marzo y, por tanto, daría pie a fijar la fecha de ese Tratado. 
158.- JULIEN, C. André, Histoire de l' Afrique du Nord-Tunisie-AlgérieMaroc. Des origines à la conquète arabe(647 ap. J. C.). Avec quince croquis et cartes. Algiers, 1931, 333 pp.

Muy interesante para una presentación sucinta de la época histórica en que aparece Agustín. Los circunceliones y los donatistas con las varias resoluciones políticas y la unión a lo religioso. Dedica un apartado a San Agustín(pp. 220-230) en lo tocante al donatismo y pelagianismo con las repercusiones en lo tocante a lo político. "Il rompit, pourtant, cette liaison sur les instances de sa mère, plus bourgeoise provinciale sur ce point que chrétienne, et qui desirait un mariage mieux assorti. Plus tard, il rappela, avec amertume, les débordement de ses jeunes années, mais continua à être assailli de visions sensuelles qu' il eut grand -peine à refouler. Il se peut que cette obsession nocturne de la chair ait contribué à lui révéler l' infirmité de la volonté humaine et la necessité angoissée de la grâce. On a même voulu y voir la chef des Confessions". (p. 221, en la 2da. Ed. revisada por Christian Courtois, Paris 1956).

159.- LAPEYRE, G. G., L' ancienne Eglise de Carthage. Études et documents. Avec une Lettre - Préface de S. Exc. Mgr. Lemaître, Primat d ' Afrique, Archevêque de Carthage. 1re. Série: S. Augustin et Carthage. Le XIVe Centenaire de saint Fulgence. Vie de S. Fulgence par Ferrand, diacre de Carthage. $2^{\text {me }}$ Série: L' Eglise du Carthage au Concile d' Ephèse. La politique religieuse des rois vandales. Ferrand, diacre de Carthage. Passion des sept moines de Capsa. Evêques, basiliques, monastères, cimitières de Carthage. Paris, Gabriel Beauchesne et ses Fils, 1932, VI-243 pp. et VIII-199 pp.

En la nota introductoria -nos dice en el vol. I- que el "estudio sobre san Agustín y Cartago ha aparecido casi enteramente en el volumen II de Miscellanea Agostiniana" (p. V). Y aquí ocupa las pp. 1-143, bajo estos epígrafes: I. El estudiante; II. El profesor; III. La conversión; IV. Las grandes luchas doctrinales: el donatismo, el maniqueísmo, el pelagianismo, el arrianismo; V. Los Sermones de Cartago; VI. El teólogo y el director de almas. En el volumen II se habla sólo incidentalmente de S. Agustín, en el segundo tema sobre todo. 
160.- MOCHI ONORY, S., Vescovi e Cittá. (Sec. IV, VI). (Biblioteca della Rivista di Storia del Diritto italiano, 8). Bologna, 1933, XXX-346 pp.

161.- VAULTRIN, J., Les basiliques chrétiennes de Carthage. Étude d'Archéologie et d' histoire. 1930. Alger, Societé historique algérienne, 1933, 179 p. Avec 24 planches.

Da información sobre las diversas basílicas descubiertas en las excavaciones y es de poco interés para San Agustín.

162.- METZGER, Gerhard, Die afrikanische Kirche. Teildruck aus der Arbeit: Die Kirche Afrikas um die Wende der 4. und 5. Jahrhunderts nach dem augustinischen Briefkorpus. Inaugural Dissertation zur Erlangung der Doktorwürde einer Hohhen evangelisch-theologisch Fakultät der Eberhard - Karts- Universität zu Tübingen. Tübingen, Albert Brecht, 1934, 81 pp.

Publica la Parte IV de su tesis sobre "la Iglesia africana" con estos apartados: 1. Die Verfassung; 2. Die Gottesdienst; 3. Die Geistlichkeit; 4. Die Gemeindefrömmigkeit; 5. Das Mönchtum. Al final da una bibliografía no amplia. La primera parte está dedicada en la dactilografiada -como anuncia p. 1, n. 1- al cisma donatista, la segunda, a las luchas pelagianas y la tercera, a la paganidad o paganismo.

163.- HÖSLINGER, R., Die alte afrikanische Kirche in Lichte der Kirchenrechtsforschung nach kulturhistoricher Methode. Wien, 1935.

164.- RODARY, P., Recherche des Inscriptions libyques dans la Region de Souk - Ahrras, en Premier Congrès de la Fédération des Sociétés savants de l' Afrique du Nord", Alger 1935, 173-181, 415-423.

Se trasladó el III Congreso a Constantina en 1937 y se publicaba en Alger 1938.

165.- ALBERTINI, Eugène, L' Afrique Romaine. Alger, Société historique algérienne, 1937, puesta al día en su texto en el 1949 por Louis Leschi, $128 \mathrm{p}$.

Con fotografías de las excavaciones, sus temas son los siguientes: $I$. Los límites de la dominación romana en el tiempo y en el espacio; II. Organización administrativa del Africa romana; III. Vida económica 
del Africa romana; IV. Los monumentos romanos de África; $V$. La vida intelectual y moral en el África romana; VI. El fin del período romano en Africa.

166.- LEYNAUD, Augustin F., Les catacombes africaines. Sousse - Hadrumete. Alger, 3 ed., Imp. polyglotte africaine, 1937, XXXIX -514 pp.

Noticia descriptiva de las diferentes catacumbas de Hadrumeto, con unas conclusiones dogmáticas sobre la inmortalidad del alma, Dios, Jesucristo, la Eucaristía, La plegaria por los muertos, La comunión de los santos, El cielo, El purgatorio, la perennidad de la Iglesia como verdad siempre antigua y siempre nueva.

167.- GAUTIER, E. F., Le passé de l' Afrique Nord. Paris, 1937.

168.- MERIGHI, A., La Tripolitania antica dalle origini alla invasione degli arabi. (Storia della Libia). Verbania, A. Airoldi, 1940, 2 vols., 322 pp. e 514 pp. con diversas pinturas.

169.- QUASTEN, Johannes, "Vetus superstitio et nova religio". The problem of Refrigerium in the Ancient Church of North - Africa, en "Harvard Theological Review" 33 (1940), 253-266.

El culto de los mártires ha tenido un amplísimo desarrollo en la Iglesia del Norte de África. Agustín es un buen testigo de ello y el autor lo cita muchas veces, casi en cada página, para concluir: "Accordingly Augustine' s support of the cult of the martyrs, and, still more, his solicitude for a worthy form of this veneration of the saints, show his understanding for the traditional piety of the people. K. Holl has already pointed out the importance of emphasizing this fact in any adequate evaluation of the work and character of the great Bishop of Hippo. The motto of Augustine's reform is most appropriately expressed in his own words: "Ut vetus superstitio consummetur et nova religio perficiatur". (Frangip. Serm. 8,5 (G. Morin, M. A., I, p. 231). (p. 266).

170.- KLUGE, O., Der Romgedanke von der Antike zur Renaissance, en "Gymnasium" 52 (1941), 38-70). 
171.- LEBRETON, Jules, Saint Augustin dans l' Afrique envahie, en "Construire" 6 (1941), 100-115.

En respuesta a las calumnias de los paganos, "Agustín expone la gran tesis que resuelve el problema de la providencia de Dios sobre los Estados; las prosperidades de aquí abajo son acordadas en recompensa por las virtudes humanas de los pueblos; esta ley aparece manifiestamente en la historia de Roma: mientras el pueblo romano ha sido sobrio, laborioso, votado al bien del Estado, ha adquirido potencia y gloria, cuando han desaparecido las virtudes antiguas, el impero romano se ha trocado en caduco" ( $p .109)$. Y a este fin expone también la Epist. 138, 17.

172.- BREZZI, Paolo, Roma nel pensiero di S. Agostino, en "Atti del V Congresso Nazionale di Studi Romani” a cura di C. Galassi Paluzzi, vol. III, 62-67. Roma, Istituto di Studi Romani, 1942, 556 pp.

En el resumen en latín dice: "Divus Augustinus, etsi Imperii Romani religionem rationemque damnavit, intellexit quantum christianae Fidei prodesse possent quae Romani fecissent, neque ullam bene constitutam rem publicam praeter illud imperium in orbe terrarum agnovit. Sed Imperium Romanum paulatim christianum factum in auguratus, aetatem quae media dicitur aliqua ex parte nuntiavit". (p. 62). Remite como prueba de ello a su estudio La concezione agostiniana della Città di Dio e le sue interpretazioni medioevali, en "Rivista Storica Italiana” 4 (1938) y el cap. "L' agostinianesimo medioevale e "Ottone di Frisinga", en "Bolletino dell' Isttuto Storico Italiano per il Medio Evo" 54 (1940).

173.- FREND, W. H. C., $A$ note on the Berber background in the life of Augustine, en "The Journal of Theological Studies" 43 (1942), 188191.

En África durante la ocupación romana se hablaban tres lenguas: latín, púnico y líbico. Y la distribución regional sería parecida a la presente en que se habla árabe y bereber (p. 188) describiendo las inscripciones descubiertas escritas en líbico y latinolíbico. Esto posiblemente diera lugar a la Africitas y tendría relación con el donatismo (p. 191). 
174.- BERTHIER, André, avec la collaboration de: LOGEART, F. MARTIN, M., Les vestiges du christianisme antique dans la Numidie centrale. (Missions Archéologiques). Alger, Imprimerie Polyglotte Africaine, 1943,233 pp et 30 planches.

En la Numidia central describe geografía, población, romanización y cristianización. Pasa luego revista a los vestigios y en la II Parte habla del culto: los edificios, las reliquias, las inhumaciones en las Iglesias, el culto según los documentos epigráficos.

175.- CHATELAIN, L., Le Maroc des Romains. Études sur les centres antiques de la Mauritanie Occidentale. (Bibliothèque des Écoles francaises d' Athène et de Rome). Paris, Ed. de Boccard, 1945, VIII- 318 pp.

Recoge los diversos estudios, hallazgos y excavaciones realizadas en los centros romanos de Marruecos. De interés general para la situación geográfica y social del período.

176.- COURTOIS, Christian, Histoire de l' Afrique du Nord, des origines à la fin du Moyen Âge, en "Revue historique" (Paris) 198 (1947), 228249

177.- COURTOIS, Christian, Bibliographie de l' histoire de l' Afrique du Nord des origines à la fin du Moyen Âge, en "Revue Africaine" 1947, 278-300.

"No se hallará aquí -escribe en el primer artículo- propiamente hablando un boletín crítico..." A pesar de esta reserva, yo espero que este ensayo de orientación a través de los principales trabajos, que desde 1939 a 1946 inclusive han precisado nuestro conocimiento de Africa del Norte antigua y medieval podrá no ser del todo inútil”.(p. 228). La amplia bibliografía en la que, sin embargo, el autor quiere ver lagunas (p. 228 y 249), se divide en: I. Estado de los períodos; II. Obras generales; III. Geografía, sociología, prehistoria, Período púnico-líbico; IV. Período romano, cristiano, vándalo y bizantino; V. Período musulmán (hasta el fin de la Edad Media).

178.- PALUMBO, A., La Chiesa d'Africa nella Romanitá cristiana, en Miscellanea di studi di letteratura cristiana antica" 1947, I, 127 -143. 
179.- BARADEZ, Jean, Fossatum Africae. Recherches aériennes sur l' organisation des confins sahariens à l'époque romaine. Préface de Louis Leschi. Paris, Arts et métiers graphiques, 1949, X- 370 pp. avec 275 illustrations.

Fossatum, limes y dirección de las vías en la Numidia con múltiples ilustraciones y aclaraciones a vista aérea y panorámica.

\section{Ambiente o medio social y político}

180.- DUFOURCQ, Albert, $L$ ' avenir du Christianisme. I. Partie: Histoire ancienne de l' Eglise. IV. Le christianisme et l' Empire IIIe siècle VIII ${ }^{e}$ siècle. Paris, 6ta.ed., Plon, 1927, 356 pp.

Dedica a San Agustín las pp. 216-249, tratando los problemas biográficos y doctrinales, situándolo en su tiempo y ambiente y, sobre todo, en el contexto histórico: La conversión, las polémicas, las obras, el valor de su pensamiento, la teoría del conocimiento, el conocimiento de la naturaleza, la Biblia y la ciencia, conocimiento de Dios, la Trinidad, el hombre, la caída y la gracia, Jesús, la Iglesia, la providencia en la Historia, la conversión del mundo: temas desarrollados con buen número de citas, aunque de modo rápido.

181.- ALBERTINI, Eugène, Un témoignage de S. Augustin sur la prosperité relative de l' Afrique au IVe siècle, en "Mèlanges Paul Thomas. Recueil de mémoires concernant la Philologie classique dedié a Paul Thomas". Bruges. Imprimerie sainte Catherine, 1930, LV - 757 pp, 1-5.

"Una nota incidental de san Agustín, en el diálogo De ordine, indica que había, al final del siglo $I V$, más comodidad y bienestar en Africa que en Italia: este texto (De ordine, $I, 3, n .6)$ no ha sido hasta el presente que yo sepa, comentado desde este punto de vista" (p. 1). Y lo comenta en ese sentido a propósito del aceite.

182.- DAWSON, Christopher, $S$. Augustine and his age. I. The dying world. II. The City of God, en "A monument to S. Augustine", London, 1930, 11-77. 
Circo, anfiteatro, palacios y demás monumentos suponían para la capital del Imperio un gasto enorme y la educación solamente para una élite de potentados económicamente. "The indictment of the spirit of hedonism and materialism which dominated Roman society runs through all the writtings of the Fathers and is supposed by many non-christian writters" (p. 22). Prosperidad y proceso de urbanización en el Imperio, división de clases sociales, la organización cívica, "el obispo cristiano era la figura dominante en la vida del tiempo" ( $p$. 31). En el II apartado narra el origen del libro, y lo señala como " $a$ livre de circonstance" (p. 43) y compara su contenido con la exposición precedente.

183.- GEROSA, P., S. Agostino e l' imperialismo romano, en "Miscellanea Agostiniana", II, 977-1040.

184.- BRUERS, Antonio, Romanità di S. Agostino, en "L' Italia letteraria", 19 maggio 1929.

185.- SEMERIA, Giovanni, La romanità di S. Agostino, en Vita e pensiero" 21 (1930), 473-482.

Habría una romanidad étnica, que no le interesa (p. 474), y otra espiritual, de inclinación e idiosincrásica. "Potremmo in conclusione parlare già a proposito di S. Agostino riaffermandogliela di una romanità cristiana o cristianizzante" (p. 475). Pero ésta la reducía a la latinità (p. 474). La caída de Roma le hace alzarse a los valores permanentes de la historia y al diseño providencial. Agustín respeta y ama la Roma cristiana y papal, "centro autorevole della Chiesa cattolica" (p. 481).

186.- SORANZO, Giovanni, La visione storica che sant' Agostino ebbe del suo tempo, en "S. Agostino", 377-404.

Discurre por las páginas agustinianas y por la Historia de Pablo Orosio, para descubrir la actitud de Agustín frente a la caída del Imperio, a la invasión de los pueblos bárbaros, a las condiciones de la Iglesia romana. Agustín es optimista y no piensa que los bárbaros puedan instaurar un nuevo orden político. No se percata -o no quiere ver- de las graves condiciones políticas en que vivía el Imperio romano en su tiempo. Son de sumo interés las páginas dedicadas a 
las "condiciones de la Iglesia romana", extraídas de las obras del Santo (p. 394-403). Sus conclusiones se alargan, pero pueden concretarse en ésta que explica a continuación: "Agostino non pende interesse alle vicende e alle condizioni del tempo, se non in quanto rispettiamo gli spirituali interessi del credente e della società in genere; evidentemente egli ha visuto la sua vita di fedele, di sacerdote e di vescovo in tutta la sua intensità; i rumori del mondo, le controversie che in esso si agitavano, finché non toccavano quelli che egli reputava i caposaldi del vivere sociale, dell' unità e della pace della Chiesa, lo lasciavano tranquilo e sereno; ma in ogni caso é un ottimista". (p. 403).

187.- BRONZINI, G., Romanità di Sant' Agostino, en "Convivium" 3 (1931), 247-261.

188.- VALLVÉ, M. , Alarico o la invasión del imperio romano del año 410. Barcelona, Alarme, 1933, 144 pp.

189.- LABRIOLLE, Pierre de, La réaction païenne. Étude sur la polémique antichrétienne du Ier au VIe siècle. Paris, L' Artisan du Livre Chartres Durand, 1934, 519 pp. 2 ed. 1942, 519 pp.

En la Parte IV dedica el capítulo III a "San Agustín y el paganismo de su tiempo"(pp. 437-464). Los testimonios los ha recogido de las Cartas, de los Sermones y luego de su obra capital De civitate Dei, poniéndolos en relación con la polémica judía y con la filosofía.

190.- PETERSON, E., Der Monotheismus als politisches Problem. Ein Beitrag zur Geschichte der politischen Theologie im Imperium romanum. Leipzig, J. Hegner, 1935, 158 pp.

191.- FUCHS, Harold, Der geistige Widerstand gegen Rom in der antiken Welt. Berlin, 1938.

Recoge los textos antiguos relativos a la oposición espiritual contra Roma vigente en los primeros siglos del cristianismo. Entre los autores coleccionados se halla San Agustín.

192.- ROBERTI, M., L' invasione vandalica nell' Africa romana. Le ragioni del succeso dell' impresa, en "Rivista di storia del diritto italiano" 11 (1938), 271-288. 
193.- ZEILLER, Jacques, Les héresies en Afrique entre la paix constantinienne et l' invasion vandale, en "Mélanges Fr. Mastroye" 1940, 101106.

194.- ZEILLER, Jacques, $L$ ' Arianisme en Afrique avant l' invasion vandale, en "Revue Historique" 173 (1934), 535-540.

El arrianismo tuvo en África ecos bastante débiles. Los pocos sermones de Agustín sobre él dan muestra de ello. Y antes de la invasión de los vándalos no fue una amenaza para la Iglesia del Norte de África como tampoco, al parecer, después de Genserico.

195.- STRAUB, Johannes von, Romanus et Christianus. Die gotische Landnahme im Spiegel der christlichen Geschichtsapologetik, en "Geistige Arbeit” 20 jul. (1939), 7-9.

Caída del Imperio Romano e impresión de Rutilius Namatianus, Synesius ep., S. Agustín y Orosio ante el saqueo de Roma del 410.

196.- HERZOG, R., Weltrechtdämmerung, en “Gymnasium” 51 (1940), 1001 -106.

Cómo sintieron la caída del Imperio romano S. Jerónimo, S. Agustín y Salviano, previéndola antes e indicando sus causas.

197.- BURGER, J. D., Augustin et la ruine de Rome, en "Revue de Théologie et de Philosophie" 30 (1942), 177-194.

198.- BARDY, Gustave, Chrétiens et païens à la fin du IVe. siècle, en " $L$ ' Année Théologique" 4/3 (1943), 457-503.

Tras una Introducción, plantea el problema de las relaciones entre cristianos y paganos en Occidente y luego de pasar revista a san Ambrosio y a san Jerónimo, lo hace con "San Agustín y el mundo pagano de África. Nectario de Calama, Máximo de Madaura, Longiniano, Volusiano"(pp. 474-483). Interesantes las anotaciones para la amistad benévola y acogedora que ha usado Agustín con todos: "Mantiene relaciones corteses con los paganos de Africa que se dirigen a él; y son ellos quienes. con mucha frecuencia, dan los primeros pasos" (p. 183). 
199.- BARDY, Gustave, Lettrés chrétiens et civilisation romaine à l' aube du Moyen Âge, en "L'Année Théologique" 3/2 (1942), 424 - 462.

Una primera parte habla brevemente de Agustín "tras la caída de Roma del 410: terror y escándalo, el pensamiento y la acción de Agustín, de Pablo Orosio, de Salviano, de S. León Magno”. Y continúa con otros autores y acontecimientos. Expositivo y de divulgación.

200.- BARDY, Gustave, Pelérinages à Rome vers la fin du IVe. siècle, en “Analecta Bollandiana”, 67 (1949), 224-235.

"San Agustín que después de su conversión y bautismo pasa algún tiempo en Roma, antes de regresar al Africa, no parece haber sido atraído por los grandes recuerdos cristianos de la capital" (p. 228). Da alguna cita aquí también y en la p. 229.

201.- LIETZMANN, Hans, Geschichte der Altenkirche. Die Zeit der Kirchenväter. Berlin, Walter de Gruyter, 1944, IV - 204 pp.

202.- LIETZMANN, Hans, Histoire de l' Eglise ancienne. T. IV: L'époque des Pères de l' Eglise jusqu' au Ve. siècle. Trad. de l' all. par A. Jundt. (Bibliothèque historique). Paris, Payot, 1949, 206 pp.

Agustín tiene una parte mínima y lo cita en las pp. 39, 73, 92, 167, 169-170 y en estas últimas hablando del monacato.

203.- LATOUCHE, Robert, Les grandes invasions et la crise de l' Occident au Ve. siècle. (Les grandes crises de l' Histoire). Paris, AubierEditions Montaigne, 1946, 324 pp.

Para el entorno, aunque no hable de san Agustín.

204.- MULLER, H., Christians and pagans from Constantine to Augustine. Part 1: The Religious Policies of the Roman Emperors. Pretoria, Union booksellers(Pty), 1946, IX - 155 pp. Part 2: The Spiritual Conflict. Pretoria, 1948, III-164 pp.

En la Primera Parte habla de la política religiosa de los emperadores romanos y cita en alguna ocasión a Agustín. En la Segunda expo- 
ne el conflicto entre paganos y cristianos y dedica el Capítulo VI a Agustín y el paganismo(pp. 105-130). Lo subdivide en una Introducción con "Agustín y sus correspondientes paganos", "El saqueo de Roma y el De civitate Dei”.

205.- CAMPENHAUSEN, Hans von, Augustin und der Fall von Rom, en "Universitas" 2(1947), 257 - 268, y en "Weltgeschichte und Gottesgericht”. Zwei akademische Vorträge über Augustin und Luther. (Lebendige Wissenschaft, 1). Stuttgart, Kreuz - Verlag, 1947, 2-18.

"Augustin will den Sinn des christlichen Glaubens an Gott gerade dort festhalten, wo er dur äussere Katastrophen scheinbar in seiner Sinnlosigkeit entlarvt wird, und er will die Auseinandersetzung mit den hier einsetzenden heidnischen Augriffen nicht bloss, wie man in Schiefer Begriffsbildung zu sagen Pflegt, "rein religiös", sondern auch politisch zu Ende führen in grundsätzlicher, kritischer Besinnung über den wahren Rang und Weit des staatlichen Lebens überhauft und vorab des jetzt so schwer erschütterten römischen Staates. Nur unter diesen zwei Gesichtspunckten, die es zu einer unmittelbaren Antwort an ihre Zeit machen, soll uns das Werk im folgenden beschäftigen” (p. 259). Y centra el estudio sobre el De civitate Dei y sus soluciones para ese "después de la guerra" que vivían.

206.- BARDY, Gustave, L' Eglise et les derniers Romains. (Bibliothèque chrétienne d' histoire).Paris, 8eme ed., Robert Laffont, 1948, 300 pp.

Esta bella obra de Bardy ofrece una visión muy clara del mundo ambiente en que se desarrolla la actividad de san Agustín. En el cap. I toca muy de cerca los "tres centros de atracción en Occidente: Milán y S. Ambrosio, Hipona y S. Agustín, Belén y S. Jerónimo”. En el segundo "los amigos paganos de Agustín", y en el tercero"La crisis del siglo $V$ " con estos epígrafes: "La toma de Roma en el 410. Reacciones de San Jerónimo y de san Agustín. La tranquilidad espiritual de Rufino.La Ciudad de Dios de s. Agustín - Las dos ciudades - Las virtudes de los antiguos romanos - San Agustín y el imperio". 


\section{El medio o ambiente familiar}

207.- BASSI, Domenico, Monica nei Dialoghi di Cassiciaco, en "Augustiniana” Napoli, 1930, 51-61.

Actividad de Agustín en Casiciaco y luego ¿Qué parte tiene Mónica en esos Diálogos? (p. 53). Recorre cada uno de esos Diálogos y en ellos va descubriendo la silueta y la parte de Mónica y el respeto de Agustín hacia sus intervenciones. El simbolismo de Mónica en los Diálogos como certeza conquistada por la fe, no por la razón (p. 56).

208.- DIJK, W. van, Augustinus en zijne Moeder. Bij het Xve Eeuwfest van St. Augustinus 1930. Amsterdam, Drukkerij “ 't Kastell van Aemstel", 1930, $40 \mathrm{pp}$.

Una conferencia publicada. Siguiendo el relato de las Confesiones va extrayendo los contactos mutuos entre el hijo y la madre, haciendo luego sus correspondencias en la liturgia de las fiestas de ambos.

209.- LEONHARDT, Baptist, Augustin und seine Mutter, en "St. Augustin" (Würzburg), 1930, 29-33.

Ateniéndose a las Confesiones, escribe poética y calurosamente sobre: "Die mahnende Mutter", o la madre que aconseja, el sueño de la madre, la madre cabe el obispo, la travesía, espíritu defensivo de Agustín, la madre de casa, la hora feliz, o sea el éxtasis, la muerte de la madre.

210.- GRÄFIN von PESTALOZZA, Hanna, Augustin und Monika. Die Geschichte von Mutter und Sohn. Darmstad, E. Hofmann und Co., 1930, $122 \mathrm{pp}$.

A modo de novela.

211.- CESARO, Maria, La Madre, en “Studium” 26 (1930), 599-607.

Sigue el relato que hace Agustín de su madre en las Confesiones y añade algunas apreciaciones personales. Hay, sin embargo, algunos apuntes que pueden interesar a más de uno: "(Mónica) lo sogna cris- 
tiano, sí, ma anche marito, magistrato, professore; lo pensa, forse, mediocremente convertito: un brav' uomo come ce ne sono tanti. Essa non è una visionaria: esperare di più, in quel momento, le sembra giustamente inopportuno e illogico. Per raggiungere tale sistemazione del figlio, ricorre a quel passo, intorno al quale sappiamo troppo poco per poterlo serenamente giudicare: l' allontanamento, ciò̀, della prima concubina, ed il fidanzamento di Agostino stesso. Perché allontanare l' Africana? Perché non legittimar, invece, quel legame, esistente già di fatto da anni? Solo considerazioni di ordine sociale ed economico hanno deciso Monica ad agire cosi? Non sappiamo questo e non lo sapremo mai perchè l' unico che avrebbe potuto spiegare la condotta sua e di sua madre, Agostino, è stato laconicissimo su questo punto”. (p. 604).

212.- MUNDING, Emmanuel, Monika und Augustinus. Ein heiliger Sohn über seine heilige Mutter, en "Benediktinische Monatschrift" 12 (1930), 261-269.

Siguiendo el relato de las Confesiones, habla de Mónica sin grandes desarrollos personales y creyendo a la narración de Agustín.

213.- STEGER, L., De authenticiteit van het gebeente van Sint Augustinus ' Moeder de heilige Monica, en "Studiën”, 113(1930), 397-404.

Los restos de santa Mónica ¿son los que se hallan én la Iglesia de San Agustín de Roma? "En dit is, wat in deze bescheiden studie $1^{\circ}$ mij te bewijzen valt. Maar $2^{\circ}$ Wat dan te denken van de groote en menigvuldige wonderen die het $H$. Overschot van Rome te beurt vielen?" (p. 397).

214.- KINON, Victor, Monique. Mystère lyrique en sept tableaux. Paris Bruxelles - Couztrai, Les éditions Jos. Vermant, 1931, 247 pp.

"En resumen, Mónica procede de un pensamiento de colaboración leal, sobre un pie de igualdad entre la Poesía y la Música. Se halla, al lado de escenas líricas, o aún puramente musicales, pasajes "hablados", que no comportan notación vocal, pero que podrían ser sostenidos por un ligero acompañamiento de cuerdas” (p. 15). No es opera, es género mixto, exponiendo en verso para representar el 
drama de la conversión de Agustín, en que ha tomado una pequeña parte Mónica.

215.- PIRARD, Pierre, Sainte Monique. (Les saints laïques). Paris, Lethielleux, s. f., 61 pp.

216.- BOUGAUD, Emilio, Storia di Santa Monica. Edizione stereotipa. Torino - Roma, Marietti, 1931, XLVIII - 363 p.

217.- BOUGAUD, Emilio, Santa Monica. Trad. del francese per E. Logi. (Opera agiografica). Siena, Sodalizio ed. Cantagalli, 1942, 301 pp.

La conocida obra de Bougaud está traducida aquí al italiano. Dado que su Introducción está fechada en 1865 puede hacerse ya el lector a la idea de la falta de crítica y de lo mucho imaginado y exagerado que se halla en estas páginas

218.- CALZA, Guido, Tra le rovine di Ostia. La Commemorazione di S. Monica, en "Bolletino degli Amici delle Catacombe" 1-2 (1934), estratto, 14 p. 2 fig.

Con estilo elevado y panegírico desarrolla los siguientes temas: $L a$ vida, la madre, la educadora, viuda ejemplar, sus lágrimas, escuchada, el último coloquio, el dolor del hijo, la tumba y el culto.

219.- LECLERCQ, Henri, Monique (sainte), en "Dictionnaire d' Archéologie chrétienne et de liturgie” 11, 2 (1934), 2233-2234.

220.- HÜMPFNER, Winfried, Monika, en "Lexikon für Theologie und Kirche" 7 (Freiburg 1935), 375-376.

221.- DORE, Peppina d. Maria Giovanna, Monica. La mamma che salva. Brescia, Morcelliana, 1938, 254 pp.

En un estilo elegante y poético, también siguiendo las Confesiones, sin mayor profundidad, presenta la figura de Sta. Mónica desarrollada bajo estos titulares: Un niño de Tagaste, El hijo pródigo, Lágrimas, Los días felices, La espléndida señora. Al final ofrece una bibliografía reducida. Cargada de imaginación, pretende asentarse siempre sobre la historia. 
222.- ZANTA, Leontine, Sainte Monique et son fils. Préface $d u R$. $P$. Sertillange. París, 8e. Édit., Plon, 1941, XI-234 pp.

Hace una recensión del libro Gustave Bardy en ' $L$ ' Annèe Théologique” 4/2 (1943), 270-271. Y el libro se desarrolla en cuatro Partes, tratando el tema de la siguiente manera: I. Parte: Mónica en el hogar: Mónica, niña y joven, y Mónica esposa; II. Parte: Mónica Madre: La madre según la carne, La Madre según el espíritu; III. Parte: Mónica educadora: Mónica viviendo - La Madre que castiga - La madre que llora y perdona - Mónica a la espera - Llamada de Dios; IV. Parte: Mónica mística - La Madre de un santo: La mística en acción sobre el plano humano - La mística sobre el plano divino - La mística paciente - La mística, abadesa de Cassiciacum - La mística filósofo - La Mística preparando al bautismo - El misticismo de Mónica - Los visionarios de Ostia.

223.- GRUMEL, V., Decouverte à Ostie d' une inscription relative à sainte Monique, en "Revue des Études latines" 24 (1946), 70 -71.

Resumen del descubrimiento de la inscripción, según L'Osservatore romano del 25 de diciembre de 1945 La relación se debía al P. A. Casamassa.

224.- HENDRICKX, Ephrem, De grafsteen van de Monica gevonden, en "Studia Catholica" 21 (1946), 176-178.

Anuncia el descubrimiento de las inscripciones sobre S. Mónica en Ostia, que había referido el P. Antonio Casamassa en " $L$ ' Osservatore romano" el 6 de diciembre de 1945. Expresa su contenido y su valor.

225.- DANEMARIE, Jeanne, Mère et Fils. Monique et Augustin. (Coll. "Les belles amours"). Paris, Éditions familials de France, 1948, 183 pp.

"Buscamos el alma de Mónica, el alma de una madre abrumada por el peso de un hijo difícil más allá de los límites ordinarios, hijo convertido ya en un adolescente pervertido, luego en un hombre sin freno, pero cuya potente inteligencia había discernido ella, y del que su fe, su amor y sus plegarias, han hecho un santo". (p. 7). Y en doce capítu- 
los sin títulos va desgranando poéticamente su vida y mostrando su ejemplo a las madres modernas

226.- GAVIGAN, John J., The mother of St. Augustine, en "The American Ecclesiastical Review” 119 (1948), 254 -280.

El mismo Agustín ha escrito las mejores páginas sobre su madre y su historia, y el autor hace un breve comentario. (p. 255). Los puntos tratados son los siguientes: El niño, La viuda, la madre, el sabio cristiano, La muerte cristiana, en un epílogo sobre el cuerpo y su traslado.

\section{Medio o ámbito personal}

\section{a. Cuerpo (enfermedad, debilidad)}

227.- LEGEWIE, Bernhard, Die körperliche Konstitution und die Krankheiten Augustins, en Miscellanea Agostiniana” II, 5 - 22.

b. Psiquismo, sensibilidad, emociones, sentimientos, pasiones, inteligencia, corazón, alma...

228.- LEGEWIE, Bernhard, Augustinus. Eine Psychographie. Bonn, Marcus und E. Weber, 1925, vii -133 pp.

He aquí su índice o esquema de trabajo: I. Die Persönlichkeitsgeschichte-Augustins: Überricht: 1. Augustins Reifejahre; 2. Jahre der Einkehr und Umkehr; 3. Augustin als katholischer Christ, Priester und Bischof; 4. Augustin als Kirchenlehrer; II. Psychologische Zusammenhänge in den Werken Augustins: 1. In den Konfessionen; 2. In den Retraktationen; 3. In den übrigen Werken. III. Augustins Persönlichkeit und ihr Verhältnis zu seiner Tätigkeit und Lehre: 1. Allgemeine Gesichtspunkte, aisschliessliche Geitesarbeit, philosophische Bestrebungen, Wertphilosophie, Religiosität, Autoritätsbedürfnis, Produktivität; 2. Die persönliche Bedingtheit der Lehre Augustins: a) Die Lehre vom Schöpfer; b) Die Lehre vom Geschöpf; IV. Persönlichkeitsanalyse Augustins; Grunzüge seiner seelischen Struktur. Schluss: Die Bedeutung Augustins. 
Por otra parte, Lange resume el contenido de esta obra en los siguientes términos: "In fesselnder Darstellung wird nun erstens die Persönlichkeitsgeschichte Augustins behandelt. Als Hauptwendepunkte treten hervor: die Hortensiuslektüre, die Bekehrung und die tiefere Erfassung der Gnade bei der Niederschrift der "Div. Quaest. Ad Simplicianum" in Jahre 397. Ein zweiter Abschnitt studiert die psychologischen Zusammenhänge in Augustins Werken, vor allein in den Konfessionen und den Retraktationen. Die daraus gewonnene Auffasung bietet die Handhabe, im dritten Teil Augustins, Persönlichkeit in ihre, Verhältnis zu seiner Tätigkeit und seiner Lehre darzustellen. Die Persönlichkeit hat die Lehre ihrer Eigenart zum guten Teil bedingt. Der vierte und lezte Abschnitt nimmt die eigentliche Persönlichkeitanalyse vor, um der Kern augustnischen Wesens herauszuschälen, und dädurch vertändlich zu machen weshalb die Persönlichkeitgeschichte so und nicht anders verlief. Zwei Probleme stehen für Augustin im Mittelpunkt: das Problem der Sünde und das Problem der Gnade. Bei ersterem erscheint als treibende Kraft die Trias: elementar - sinnliche Leidensschaftlichkeit, ein sehr empfindsames Gewissen und Angstlichkeit. Erlebnishintergrund des Gnadenproblems ist die als gnadentat Gottes gedanklich verarbeitete "Bekehrung" und besonders die grosse Gnadenbedürftigkeit zur Zeit der Abfassung der Konfessionen. Treibendes Moment ist hier faste ausschliesslich die ungeheuer starke sexuelle Libido, die vergebens gegen das fest gegründete sittliche Gebot ankämpft” (p. $400 \mathrm{de}$ Lange).

229.- LANGE, Hermann, Eine Psychographie Augustins, en "Scholastik" 1 (1926), 400-411.

Un largo comentario a la citada obra de De Legewie. Le sigue paso a paso y al final escribe: "So kann man die in mancher Beziehung ausprechende Psychographie doch nur mit sehr gemischter Freude aus der Hand legen. Den Grund zu den besprechenen unrichtigen Beurteilungen sehe ich dann, dass Dr. Legewie einmal keine genügend umfassende Kenntnis der Werke Augustins besitzt, sodann Naville zu sehr getrant hat, endlich als Arzt wohl auch etwas von der überall sexuelle Triebfedern witternden Psychoanalyse beeinflusst wurde" (p. 411). 
230.- BAXTER, J. H., Ubi est illud? (Interpretation d' un texte de saint Ambroise de Fastidiis et de saint Augustin, en "Bulletin du Cange" I (1924), 51.

231.- BAXTER, J. H., Colloquialisms in St. Augustine, en "Archivum Latinitatis Medii Aevi” 3 (1926-1927), 32 -33.

"From this date, of course, Augustine lies a little outside the scope of this Bulletin and of the eventual Dictionary of Medieval Latin, but it is worth while collecting a few of his colloquial or slangs expressions, both as a prelude to similar articles drawing upon later preachers, and as a contribution to our knowledge of popular speech. Not all the expressions quoted can be called slang; I have included proverbial and everyday phrases for completeness" (p. 32). Y cita esas expresiones en latín, y la obra de san Agustín de que proceden

232.- SUARES, André, Misére des Heil. Augustin. Dt. von W. Luetjens, en "Neue Schweizer Rundschau" 22 (1929), 672-677.

233.- BOCK, J. P., De charactere S. Augustini, en "Bogoslovska Smotra" (Zagreb) 18 (1930, 393-406.

234.- FOUQUEAU, E., L' Âme de Saint Augustin d' après les Confessions. Orléans, Secrétariat des Oeuvres, $1930 \ldots$

235.- COMEAU, Marie, L' evolution de la sensibilité de saint Augustin, en "Saint Augustin"(Paris), 21-51.

"Agustín impregna su enseñanza de su vida, de sus sentimientos personales" (p. 23). Su sensibilidad no debe hacer olvidar su capacidad intelectual. "La evolución psicológica de S. Agustín es señalada por todos sus biógrafos" (p. 27). "La sensibilidad, según ley común, sufrió el contrapeso de su temperamento" (p. 29). "Una extrema impresionabilidad, una vulnerabilidad excesiva en relación con los sufrimientos pueden en parte explicar la susceptibilidad, las desconfianzas de Agustín" (p. 31). "Una imaginación viva y ardiente, y una tremenda sed de ser comprendido" (p. 32). "En cierta medida ante los demás se torna misántropo" (p. 33). Y sigue examinando con ojo penetrante esa evolución hasta el fin de su vida. 
236.- GISQUIÈ RE, Emmanuel, Harmonia et synthesis in ingenio et indole S. Augustini, en "Augustiniana"(Averbode), 82-105.

Primero estudia el método intelectual de Agustín, que siendo metafísico se adecuaba a la realidad y luego investiga la índole de su espíritu sintético: "Qua duplici investigatione ad duas pariter conclusiones me confido inducere posse, nempe primo: synthetice jugiter procedere Hipponensem in perscrutanda realitate, eam videlicet totam simul prouti in rerum natura invenitur, acuta suae mentis acie penetrando; -secundo: summopere attendendam dotem animae ejus esse miram harmoniam et amicam consociationem acutissimi ingenii et affectus ferventissimi; quin unum alteri noceat vel alterius provintiam indebite pervadere nitatur" (p. 83). Y lo ha hallado en la síntesis armónica que realiza su alma entre Dios y el hombre (p. 105).

237.- GUILLOUX, Pedro, El alma de San Agustín. Traducción de la 2da Edición francesa por Ignacio Núñez. Barcelona, Luis Gili, 1930, 329 pp.

Conocida la obra en el original francés, nos basta con recoger los títulos de las cinco Partes en que está dividido el libro: La infancia sin preocupaciones. La juventud inquieta. El recogimiento del alma. El Pastor de Hipona. El Apologista. Entresaca los problemas principales de la vida de Agustín y los trata con destreza.

238.- LABRIOLLE, Pierre de, L' âme de S. Augustin, en "La Vie spirituelle” 24 (1930), 45-61.

Agustín era físicamente de complexión débil y enfermiza y en sus obras, aún en sus Confesiones, se ha mostrado muy discreto al hablar de sí mismo y no se ha pintado ni alabado: "Lo que a tantas páginas de Agustín da su encanto extremo, su tonalidad del todo especial, es la potencia de amar de que dispone" (p. 50). Y se detiene unas páginas en el amor y en la amistad de Agustín: "El fondo más rico de humanidad, de moderación, de bondad, he ahí lo que se descubre en Agustín, cuando se quiere llegar al hombre a través de sus libros" (p. 54). "Un corazón caluroso, apasionado: y ahora veamos un poco el espíritu: Agustín fue un gran intelectual, quiero decir un hombre apasionado por las ideas, por la controversia” (p. 56). Agustín en el mundo de las ideas se mueve plenamente a su gusto. "En el conoci- 
miento de los hechos, de los conocimientos positivos, no tiene siempre la misma facilidad ni la misma curiosidad de espíritu. La curiosidad: he aquí una palabra que no amaba" (p. 58). En el fondo dulce de Agustín queda siempre algo del dialéctico duro (p. 59).

239.- MARTINDALE, C. C., $A$ sketch of the life and character of St Augustine, en "A monument to Augustine", 79 - 101.

Luego de decirnos adonde hay que recurrir para este estudio del carácter de Agustín, se atiene un poco a los "dos Agustines", el de los Diálogos y el de las Confesiones, el filósofo y el místico. "I see, then, Augustine, at Cassiciacum, spending part of his day in the care of his friend's estate; part - out of doors or (when it rained) in the bathing -hall-in vigorous, light-hearted disputation; part at night or in the early morning, praying, weeping, thanking, exulting his faith. The two accounts of those early days of christian life are perfectly compatible so far as psychology goes: and of both I will make use. I believe that the theory of the "two Augustines" will soon prove to have occupied but a brief period in Augustinian study" (p. 85).

240.- MISCH, Georg, Geschichte der Autobiographie. I Band: Das Altertum. 2 ed. Leipzig und Berlin, G. B. Teubner, 1931, 472 pp.

Dedica un amplio estudio a las Confesiones(pp. 402-440), como obra autobiográfica, analizando bajo ese ángulo, sus motivos, su composición, su estilo y sus relaciones con los diálogos. Y luego en otras páginas examina las Retractationes ( $p p$. 455-462), en lo pertinente a su autobiografía intelectual. Es una "vivencia" lo que se narra. "Unter den Motiven von Selbsbiographien erscheinen nicht selten die ins Leben einschneidenden Ereignisse welche den Einzelnen zwingen, aus der Gewonheit des Alltags herauszutretten: Ahnungen des Zusammenhanges der eigenem Existenz tauchen aud und wollen sich in der Betrachtung sammeln. Aber niemals wieder in unserer Geschichte ist diese Notwendigkeit so tiefreichend gewesen wie bei Augustin. Denn seinem überlegenen Geist wurde die innerliche Abwendung von seinem bisherigen Dasein, von alladem, was an Glück und Leidenschaft um Wünchen inn sommächtig in der Welt gehalten hatte, euer Ausgangspunkt einem Selbstbesinnung, welche bis in die Epoche seiner theologischen Kämpfe im Mittelkpunkt seiner Lebensarbeit blieb und ihm in dem einsamen Dasein, das er sich 
erwählt hatte, das Verständnis seiner religiös-sittlichen Erfahrung und des wharen Gehalts seiner Existenz ewingen vollte. "Ich habe Arbeit, ständige Arbeit in mir selbst; ich bim mir ein Grund von Schwiengkeiten und übergrossen Schweisse geworden"(Confess. X, 16, 25). Vor diesem wesentlichen Motiv, das die Ausbildung seiner Autobiographie bestimmte, tritt alles Zurück, was ihr an äusseren, durch die Bezeichnungen zur Mitwelt gegebenen Anlässen mit den andern Selbstdarstellungen dieser Zeit gemeinsam war" (pp. 402-403).

241.- JANSSENS, Alois, De geest van S. Augustinus, en "Ons Geloof” 24 (1938), 302-311.

Ik zou, naar best vermogen, het karakter van den grooten Afrikaan, den vorm en aauleg van zijn geest, zijn innerlijk wezen willen bescrijven"( $p$ 303). Y sigue su vida, según las Confesiones, desprendiendo de sus textos cuanto pretendía.

242.- BREZZI, Paolo, Sulla personalità di S. Agostino, en "Rivista di Filosofia Neo-scolastica" 31 (1939), 243 -262.

"El centro irradiador o, para decirlo mejor, el punto de partida de la ansiosa e incesante búsqueda agustiniana está representado ciertamente por el problema de la felicidad, entendiendo esta última como la plena realización del propio ser" (p. 243). Y esa felicidad busca a Dios y el descanso en El, la paz celeste que es paz completa, pero que en el mundo se encuentra turbada. "Amor de Dios y apostolado externo no se excluían en él, uno de los términos no ocupaba su ánimo hasta tal punto que arrojase de él al otro; estos dos órdenes de ideas coexistían al flanco uno de otro, más aún dialécticamente fundidos, y tal característica representa el aspecto más saliente del pensamiento agustiniano" (p. 250). Esta visión la estudia luego en la doctrina agustiniana sobre la sociedad civil y la sociedad religiosa.

243.- BARDY, Gustave, $L$ ' âme de saint Augustin, en ' $L$ ' Année Théologique” 1 (1940), 3-42.

"Nos sentimos felices de poder dar al principio de este fascículo un capítulo, el último de la nueva Vida de san Agustín que aparece en este momento en las Ediciones de la "Bibliothèque Augustinienne" (p. 2). El programa de este capítulo está claro: La humanidad de Agustín: 
Un genio muy próximo a nosotros. Hombre de su ambiente. Restos de una educación cerrada. La religión de Agustín: La acción universal de Dios. Optimismo. La inteligencia de Agustín: Su itinerario hacia Dios. Espíritu más intuitivo que dialéctico. De la fe a la inteligencia. Inteligencia, don de Dios, su pensamiento se mueve en una atmósfera de visión. El corazón de Agustín: Su potencia de amar. Sus amistades cristianas. Su entrega o su sacrificio de obispo. Dios, verdadero centro de su corazón. Dios fuente de felicidad. El amor. El amor tempera la doctrina”. Así en el sumario de la p.3.

244.- RODRIGUEZ, C., El humorismo de San Agustín, en "La Ciudad de Dios” 154 (1942), 213 - 236.

245.- COURCELLE, Pierre, Les premières Confessions de saint Augustin, en "Revue des Études latines" 21-22 (1943-1944), 155 - 174.

"Me ha parecido posible por aproximaciones de textos sistemáticos aportar algunas precisiones al debate, en el que cada uno corre el peligro de partir de una idea preconcebida. En efecto, dos páginas de los tratados de juventud tienen el cariz o el aspecto de una confesión avant la lettre. Una del De beata vita (386) va desde la lectura del Hortensius a la discusión del puesto de retórico; la otra del De utilitate credendi (391-392) va desde la conversión al maniqueísmo a la conversión al neoplatonismo" (pp. 155-156). Pone en relación estos dos textos con las Confesiones.

246.- MORICCA, Umberto, La conversione di S. Agostino, en Il mondo classico” 11 (1941) $232-253$.

247.- GULLOUX, Pedro, El alma de san Agustín. Trad. del francés por J. Núñez. Barcelona, 2da. Edición, L. Gili, 1947, 240 pp. Vid. nº 237.

\section{Amor y amistades (amigas y amigos y demás...)}

248.- FARAONI, G., Virgilio e Agostino dinanzi alla donna, en "Augustiniana”, Napoli 1930, 113-115.

" $\grave{E}$ da augurarsi che in qualche altro studio si ricordino dignamente le donne, su un S. Agostino raccolso il suo cuore e il suo pensiero. $\mathrm{Ne}$ 
avremo per conclusione un parallelo sul vario modo dei due Grandi di considerare e apprezzare il valore femminino" (p. 113). Sin textos hace una breve exposición y concluye: "S. Agostino, da che è salvato dalla rea fiumana del manicheismo pagano e da quello che sempre ribolle, e minaccia, vede, sente, celebra commosso la nobiltà della donna cristiana e affretta la nuova legislazione a difesa dei sacri diritti della donna".

"Negli esametri virgiliani la donna dà un ritmo che sfiora e accarezza l'orecchio".

"Nelle celebrazioni di Agostino, un canto che purifica e sublima $i$ cuori” (p. 115).

249." LESAAR, Heinrich Hubert, I. Alypius, pp. 220-232. II. Der Heilige Augustin in seinem Umgang mit seinem Mitbrüdern, en "Miscellanea Augustiniana”, pp. 233-241.

"Quizás sea mucho afirmar cuando se dice: "Sin la amistad de su paisano Alipio, Agustín no habría llegado a ser el gran Santo Padre de la Iglesia" (p. 220). Sin embargo, ha tenido un papel muy importante en su vida y en su obra. Lesaar escribe aquí una especie de biografía de Alipio en sus relaciones con Agustín, ateniéndose, sobre todo, a los relatos del Obispo de Hipona sobre la amistad que los unía. Las citas están tomadas de las Confesiones y de las Cartas principalmente.

Agustín ha sido un Padre para sus confratres, que eran sus hijos y ha vivido por ellos y para ellos. Examina diversas etapas en esa vida de Agustín pero en todas ellas aparece la misma conclusión, con que se inicia el estudio:"Dieses "Selig miteinander" war Augustins Lebensprogramm gleich von jenem glücklichen Augenblick au, wo das Gnademwort "Nimm und lies" ihn den lezten Wellenschlag zur Fahrt in den Hafen der "Ruhe in Gott" gegeben hatte. Schon diese erste Fahrt hatte er nicht einsam gemacht; ganz eng mit ihm verbundem, vom gleichen Gnadenstrom getragen, schritt dicht an seinerleite sein "Herzensbruder" Alypius sein trautester Weggenosse vor wie nach seiner Bekehrung der erste seiner "Mitbruder" (p. 233). Agustín estaba dotado de una naturaleza social, con una potencia sugestiva de atracción. "Augustin ist kein religiöser Egoist; sein Leben und Wirken ist ein Leben, ein Arbeiten, ein Schopfer für andere; sein Kämpfen für die Wahrheit will als Siegespreiss nicht anderes als die Liebe. Augustin ist Philosoph un Theologe, Schüler Platons und des hl. 
Paulus; vor allem aber ist er Seelsorger”. (p. 234). Y lo primero lo es de sus "confratres", a quienes sirve "corde, et voce et litteris"(ib.).

250.- SIZO0, A., The Year of Alypius' Birth, en "Vigiliae Christianae" 2 (1948), 106-108.

Alipio, nacido el año 363, sería nueve años más joven que Agustín.

251.- CAZzULANI, Piero, Il sentimento dell'amicizia in S. Agostino, en “La Scuola Cattolica” 59/2 (1931), 292-299.

"Las páginas y los pasos de sus obras que extraen de su familiaridad con este argumento un calor de vida, indicador de una naturaleza $y$ de un corazón, son por su adhesión inmediata a una realidad perenne de la naturaleza humana, de aquellas citadas por Duchesne. Dios lo dotó de una afectividad exquisita y él la cultivó con intensidad, la vivió con espíritu transportado. Los nombres más familiares en aquel drama psicológico que denominó "Confessiones" son: Alipio, $\mathrm{Ne}$ bridio, Verecundo, Romaniano, sus amigos queridos. $Y$ con los nombres baila el alma, la personalidad, la vida palpitante en comunión de afectos, de ideas, de gustos, de alegrías, de conatos y esfuerzos, de experiencias, de suerte que el libro concluye por ser un poco la historia de ellos" (p. 292-293). "La influencia de los amigos sobre el ánimo y la vida de Agustín fue grandísima" (p. 294).

"La vida monástica se convierte ahora con su recogimiento, con su separación del mundo, con su abandono íntimo y total a Dios, en su ideal más ardiente. Lo realizará en Tagaste” (p. 295). Agustín ha ido purificando su amistad -ahí están las Cartas-, hasta llegar a la "charitas". La Epístola 258 a Marciano es significativa a este respecto. "Al Agustín obispo se le abrieron nuevos y más vastos horizontes por vocación y por deber: la universalidad de su "charitas" -centro de su nueva personalidad-abraza a todos los hermanos en Cristo. No olvida, empero, a los fieles, a los íntimos, a los "antiquissimi amici". ¿Sería, pues, excesivo afirmar que la amistad como la entendió él, contribuyó a preparar su multiforme y sacrificado apostolado? Que la amistad fue el preludio de aquella "charitas" que es a la vez camino hacia la luz - "Unde non erimus in tenebris? Si amemus fratres".(In Epist. Joann. tr. 2, 2)- y norma de acción, poema de pasión: "Dilige, et quod vis fac"? (Ib. tr. 7, 8) (p. 299). 
252.- CONCETTI, Nicola, De Aurelii Augustini adolescentis concubinatu, en "Religión y Cultura" 15 (1931), 359-364.

253.- BERKEL, Emmanuel van, Vriendschap naar Sint Augustinus, Bewerkt door- - . Ter Inbeidingdoorc. Van Kerkhove. Tielt, Drukkerij - uit geverij Lannoo, 1937, 63 pp.

"Dat will dit heel bescheiden boekje U leeren komen. Het is dus een gids om U te leiden naar 't schoonste hoeksken van uw leven. En die gids is dan niemand minder dan Augustinus zelf, de Heilige, die met zijn hart in de hand afgebeeld, het best de ware liefde ende schoonste vriendschap heeft gekend.

"Laat liefde en vriendschap zich aan geen stelsels binden, toch moeten ze bovenal verstandig zijn. Kan vriendschap immers niet open bloeiën schoon en rijk, dan gaat ze dood aan armoe en zijn twee harten voor immer de warme vriendschap kwijt! .

"Aan de hand van Augustinus' leer zal uw vriendschap, diep en rijk, een blijvende stema ensterkte voor U. were” (p. 5-6).

254.- BERKEL, Emmanuel van, Augustins Vriendschap. (Uitg. Van het Geest Groot genootschap, 550). Nimegue, Dekker \& Van de Vegt, 1938,59 pp.

255.- NOLTE, Venantius, Augustinus Freundschaftsideal in seinen Briefen. Unter Hereinbeziehung seiner Jugendfreundschaften gemäss den Philosophischen Schriften und den Confessionen. (Cassiciacum, 6). Würzburg, Rita Verlag, 1939. 124 pp.

Tras una Introducción, divide la obra en tres grandes apartados: Las amistades juveniles de Agustín, El ideal de la amistad como fundamento de sus Cartas, El ideal de la amistad en el más elevado sentido, a saber, "Corpus Chrysti Mysticum". Y así expande sus partes en los capítulos siguientes: I. 1. Las amistades "sensibles", las "Neigungsfreundschaft"; 2. La amistad espiritual de Agustín con Alipio; 3. La vida de amistad en Milán; 4. Los amigos en Casiciaco.

El segundo apartado lo introduce con unas consideraciones y así cap. 2. La amistad bascula hacia aspectos intelectuales; 3. La amistad bascula hacia la "christiana caritas"; 4 . Estrecha relación del ideal de amistad y la "mutua caritas", estudiando su contenido y formas con las cartas y en ellas, en especial a Nebridio y S. Jerónimo. Y al final 
brevísimamente (pp. 120-124) hace una somera presentación del influjo de ese ideal en la posteridad, en el De spirituali amicitia, sobre todo del abad Aelred von Rieval.

256.- MUYS, Albert Pieter, De briefwisseling van Paulinus van Nola en Augustinus. Academisch Proefschrift. (Vrije Universiteit te Amsterdam). Hilversum, J. Schipper Jr., 1941, 282 pp.

En la Introducción habla de Paulino de Nola, del principio de la correspondencia y la consagración episcopal de Agustín, y luego de la correspondencia mutua y del estilo de la misma. Sigue la traducción de las Cartas con análisis gramatical y comentario.

257.- CHATILLON, François, Dardanus et Théopolis (409-417), en "Bulletin de la Société d'Études historiques, scientifiques et litteraires des Hautes - Alpes" 62 (1943), 29-151.

Las informaciones sobre Dardanus, prefecto del pretorio de las Galias en el siglo V provienen en parte de san Agustín. Un apartado, el 5to., lo dedica "al amigo de San Jerónimo y de S. Agustín"( 414-417). En lo tocante a Agustín estudia : Retrato del corresponsal de san Agustín - San Agustín no conocía a Dardanus -La Carta de san Agustín es una réplica a la de San Jerónimo - Por qué Dardanus ha escrito a San Agustín. En cuanto al contenido de las Cartas se descubre "sus tendencias antipelagianas”, “Dardanus pelagiano?”, "Las tres cuestiones de Dardanus. Siguen algunas notas: Agustín contra Jerónimo, Los conversos del siglo V, Exigencias de los laicos - La mística de la Ciudad Teópolis = ciudad de Dios era conocida en ese tiempo. Y Dardanus ha intentado llevarla a su realización.

258.- MERKEN, A., Saint Augustin et ses amis. Mémoire de licence presentée à l'Université de l'Etat à Liège, 1945.

259.- GAVIGAN, John J., St. Augustine's friend Nebridius, en "The Catholic historical Review" 32 (1946-1947), 47-58.

Con las Cartas y las Confesiones retrata la figura de Nebridio tal como aparece en las fuentes. Artículo muy completo en las referencias con su texto a pie de página. 
260.- FABRE, P., Saint Paulin de Nole et l'amitié chrétienne. (Bibliothèque des Écoles françaises d' Athène et de Rome, 167). Paris, E. de Boccard, 1949, XIX - 396 pp.

261." POULSEN, Frederik, Saint Augustin et ses élèves, en "Hommage à Joseph Bidez et à Franz Cumont". (Collection Latomus, vol. II). Bruxelles, Latomus “Revue d' Études latines”, 1949, 392 pp, 271-276.

Breve recuerdo de los días de amistad vividos por Agustín con sus discípulos en Casiciaco. "Agustín amaba a sus amigos con una ternura casi femenina" (p. 272). "El rico humanismo de Agustín le ha protegido contra el ascetismo y la vida de eremita que tentaban a muchos conversos de entonces, por ejemplo Basilio y Juan Crisóstomo"... "Agustín sentía, sobre todo, que era su deber vivir para los otros, sin aislarse en su propio interés o en el de la religión" (p. 274). "Agustín - concluye- y su círculo de estudiantes nos enseñan el valor de una antigua cultura, aún si sus condiciones de prosperidad están completamente modificadas. Es lo mismo que hemos visto en nuestros días en que una juventud sonriente, pero de espíritu serio, estaba dispuesta a sacrificarlo todo, aún la vida, por sus convicciones, por el amor sapientiae, el amor de la inteligencia y de la verdad, que da la certeza confiada de seguir el buen camino" (p. 276).

\section{La relación con San Jerónimo}

262.- VATHAIRE, J. de, Les relations de saint Augustin et de S. Jerôme, en "Miscellanea Augustiniana", 484-499.

Un breve planteamiento de la personalidad de uno y otro y de su entorno, y entra en el tema en que diferían que era la autoridad de los Setenta que Agustín defiende y que Jerónimo, a los ojos de Agustín, con su traducción directa del hebreo, pretendía menguar o anular (p. 486). Luego el incidente de Antioquía los divide nuevamente (p. 487). Expone el pensamiento y las incidencias de esa correspondencia mutua, en la primera etapa, y en la segunda, a partir de la lucha pelagiana, en que aparece la paz y el acuerdo entre ambos. "Estos dos espíritus - dice el autor-, cuya "armadura interior era la misma” diferían demasiado por sus métodos, sus tendencias, 
sus afinidades secretas, por lo que sus relaciones, siempre leales, siempre fueron fáciles. Se admiraban y se atraían, como no cesan de repetirlo en sus cartas, pero en el fondo se temían un poco, o más bien temían la parte de lo desconocido que sus múltiples desemejanzas proyectaban infaliblemente ante ellos.

"Sabio muy concienzudo, Jerónimo hacía de la prudencia crítica un deber; Agustín parecía más bien que hacía de ella un escrúpulo. En muchos lugares, y aún una o dos veces en el curso de su correspondencia, Jerónimo confiesa sus dudas, Agustín no las considera serias, afirma y cree. El erudito se detiene atentamente ante las primeras dificultades y no quiere construir amplios comentarios morales más que una vez seguro del sentido literal, el filósofo lleno de facilidad en el dominio de las ideas y siempre dispuesto a irrumpir, no tiene en el terreno de los hechos verdadero interés ni siquiera curiosidad de espíritu (p. 486).

"Jerónimo debía pensar sólo muy raramente en el tema de la amistad. Mientras que en la amistad de Agustín se percibía siempre una nota de confianza, que, aún muy viva, llevaba con ella una gran seguridad, garantía de su paz, mientras que el afecto que esperaba de los otros, lo quería siempre verdadero y sin disfraz, Jerónimo que tenía un pudor extremo de sus sentimientos íntimos, una sensibilidad tan salvaje como emotiva, Jerónimo que siempre identificaba un personaje con sus principios y no lo separaba nunca de su trabajo, de su causa, como él decía, Jerónimo no garantizaba a nadie una amistad sin pliegues y podía pasar con una convicción ardiente, de la gran ternura al ataque más vigoroso. No se creía seguro de sus amigos más que cuando era su maestro, Agustín no desconfiaba jamás desde el instante en que se había entregado, los consideraba como la mitad de su vida. Su misma manera de buscar la verdad denotaba las aspiraciones diferentes de su corazón. Agustín, este converso tan fino, tan eminentemente especulativo, tan radiante de serenidad, persigue la verdad como en una visión apasionada en que el ser todo entero se vierte, en que se adhieren todas las fibras del alma. La abraza con esa mezcla de compunción y de audacia serena cuya marca impregna toda su obra. Esta actitud asegura la perseverancia. Jerónimo, con una rectitud que parece casi estricta, jtan comprometida está en su vida!, ama a la verdad como a una virgen pura, cuya custodia le ha sido confiada. Siempre atacada, la defiende siempre, dado que falla y no sueña con medir sus golpes" (p. 492-493). 
263.- BRUYNE, Donatien de, La correspondance échangée entre Augustin et Jerôme, en "Zeitschrift für die neutestamentliche Wissenschaft und die Kunde der älteren Kirche” 31 (1932), 233-248.

Estudio cronológico y de contenido y manuscritos de estas Cartas. Un examen crítico que le conduce a las siguientes conclusiones: "Desde el punto de vista religioso, psicológico, científico y literario, estas cartas se sitúan entre las más interesantes de la literatura latina. Se ve a los dos mayores genios de esta época pintados al vivo y por ellos mismos. Uno une a una erudición y una habilidad incomparable un estilo brillante, lleno de brusquedades y de dulzuras. El otro tiene un estilo más tierno, más sereno, un poco "fatigant" = fastidioso (cansado, fatigado), pero tiene un corazón más amante, un alma más sincera, una inteligencia más penetrante. $Y$ estos dos hombres al entrar en conflicto, despliegan todos los recursos de sus talentos!" (p. 247).

264.- AUVRAY, Paul, Saint Jerôme et saint Augustin. La controverse au sujet de l'incident d'Antioche, en "Recherches de Science Religieuse" 29 (1939), 594-609.

"Precisamente trataremos de orientar al lector dando una rápida ojeada a los documentos sobre los que tendremos que discutir. Nuestro estudio únicamente abordará la posición doctrinal de los dos adversarios, pero no encarará entre los diversos objetos de su controversia más que la cuestión del incidente de Antioquía" (p. 595). No se detiene, pues, en el contenido psicológico de la controversia. Y estudia la posición de S. Jerónimo y la de San Agustín, con "cuatro actos en esa controversia: 1. Una exposición de Jerónimo en el 389(Comm. De Gal.); 2. Un ataque de Agustín en dos recensiones poco diferentes (Epist. 28 y 40), hacia 395 y 397; 3. Una respuesta de Jerónimo (Epist. 75), en el 403; 4. Un nuevo ataque de Agustín(Epist. 82), el 405, seguido de algunas alusiones nacionales" (p. 396).

265.- SIMARD, Georges, La querelle de deux saints. Saint Jerôme et saint Augustin, en Revue de l'Université d'Ottawa" 12(1942), 1538.

Expone brevemente la vida de uno y otro, hasta que llegan a la controversia: "Yo haré notar que se trata aquí menos de verdades que de maneras. Jerónimo se engaña, se entiende y Agustín es aprobado después de quince siglos por todos los comentaristas. Mas en rigor no se 
es imperfecto o santo, porque se yerre o se tenga razón. Son las maneras de pensar y de hablar, es la caridad, las que revelan la virtud. Así nos aplicamos en la reproducción de los pasajes que revelan los caracteres más bien que el saber. Se ruega no olvidarlo" (p. 19). Y comienza con las citas más importantes de las cartas mutuas con breves anotaciones que las introducen, para concluir: "He aquí por qué Agustín puede servir de modelo y ejemplar a quien decide santamente consagrar su palabra o su pluma al servicio de la Iglesia y de su país. Mientras que Jerónimo, polemista discutido, será siempre la tentación de los luchadores que, en tanto aparezca la verdad, aman la vehemencia, la rudeza y la ruptura" (p. 38).

266.- MORIN, Germain, A propos d'Asterius "episcopus Ausedunensis" disciple de saint Jerôme, en "Revue Benedictine" 56 (1944-1945), 5-8.

Tal vez hubiera que identificarlo con el subdiácono que trajo las cartas de Jerónimo a Agustín, y que fue elevado poco después al episcopado (Epist. 82). 